\section{A NEW HOME FOR THE PEARY METEORITE.} T WALTRR L. BEASLEY

Ahnighito ("The Tent"), the giant meteorite discovered by Lieut. R. E. Peary in Greenland in 1894 has been remove from its rather secluded position on Cob Dock, in the Brooklyn navy yard, and more strikingly exhibited on a mounted pedestal under the entrance arch of the Museum of Natural History, the two lesser ones (the "Woman" and "Dog"), companion meteorites found at the same time,

having been previously installe in the interior. According to the legendary records of the present natives these three masses were originally an Innuit woman, her dog and tent, who were hurled down from the sky by the evil spirit. On account of the extreme high latitude in which the meteorite was found, namely, Melville Bay, thirtyfive miles east of Cape York, North Greenland, coupled with its great size, uncontrovertible celestial origin, and the human associations surrounding the same, Ahnighito can be fittingly classe as the world's largest and most famous meteorite which has so far fallen on the earth's surface and been weighed. Its nearest rival is Bacubirito, of the State of Sinaloa, Mexico, whose weight has not yet been determined, but which, however, is conjectured to be far below the tonnage of Ahnighito. The new position of the noted meteorite displays its size and shape to marked advantage, the size rendering it conveniently accessible to the general public and scientists for examination. While it require many weeks of patient and laborious work for Lieut. Peary and his band of Eskimo helpers, with limited tools, to dislodge the mighty mass from its position of centuries in the Polar worle and to safely get it into the hold of the "Hope" for its long voyage to civilization, the second moving of Ahnighito, measuring eleven and a half feet in length, seven feet six inches wide, six feet thick, and tipping the scales at thirty-seven and one half tons, was, with the aid of up-to-date appliances,

speedily conveyed and set down in its new home in a day's time. At the foot of West 50th Street, North River, a wrecking barge, with a huge derrick, brought the meteorite from the navy yard and swung it upon the contractor's wagon, drawn by twentyeight horses. The transportation charges on this precious mass amounted to over $\$ 500$. The big meteorite is of especial scientific interest insomuch as its genuineness has been passed upon by the most celebrated experts of Europe. Fragments were sent to Profs. Fletcher, of the British Museum, Weinschenck, of Munich, Brezina, of Vienna, also Prof. Salisbury, of the University of Chicago. These high authorities pronounce the pieces examine to be of extra-terrestrial origin and belonging absolutely without doubt to a meteorite, as the topography of the surfaces examined in detail possess all the distinctive characteristics which mark the heavenly bodies and are not found in any other stones or metallic masses on the earth's surface. The analysis by Prof. Whitfield of the American Museum showed that it contained 91 per cent of iron and 7 per cent of nickel. Th $\mathrm{T}$ color is a dark brown or bronze. On $\mathrm{O}$ side is wedgeshaped, the opposite tabular. When discovered it was sunk in the earth with the wed ge side down. According to Prof. Salisbury, a member of the Peary expedition, the meteorite evidently fell on glacier ice, when ice covered $t h e$ whole region where it lay. On the melting of the ice the meteorite was let down upon the sur face in the position where it was found. half buried.

It is thought that a considerable portion of the meteorite has been removed by chipping off the fragments by successive generations of primitive natives in fashioning their crude implements for hunting land and sea-animals, their only chance for subsistence. Thus the big meteorite has been of great economical value to an entire aboriginal tribe isolate for centuries from civilization, the most northerly and smallest upon earth, whose habitat is entirely barren of metal.

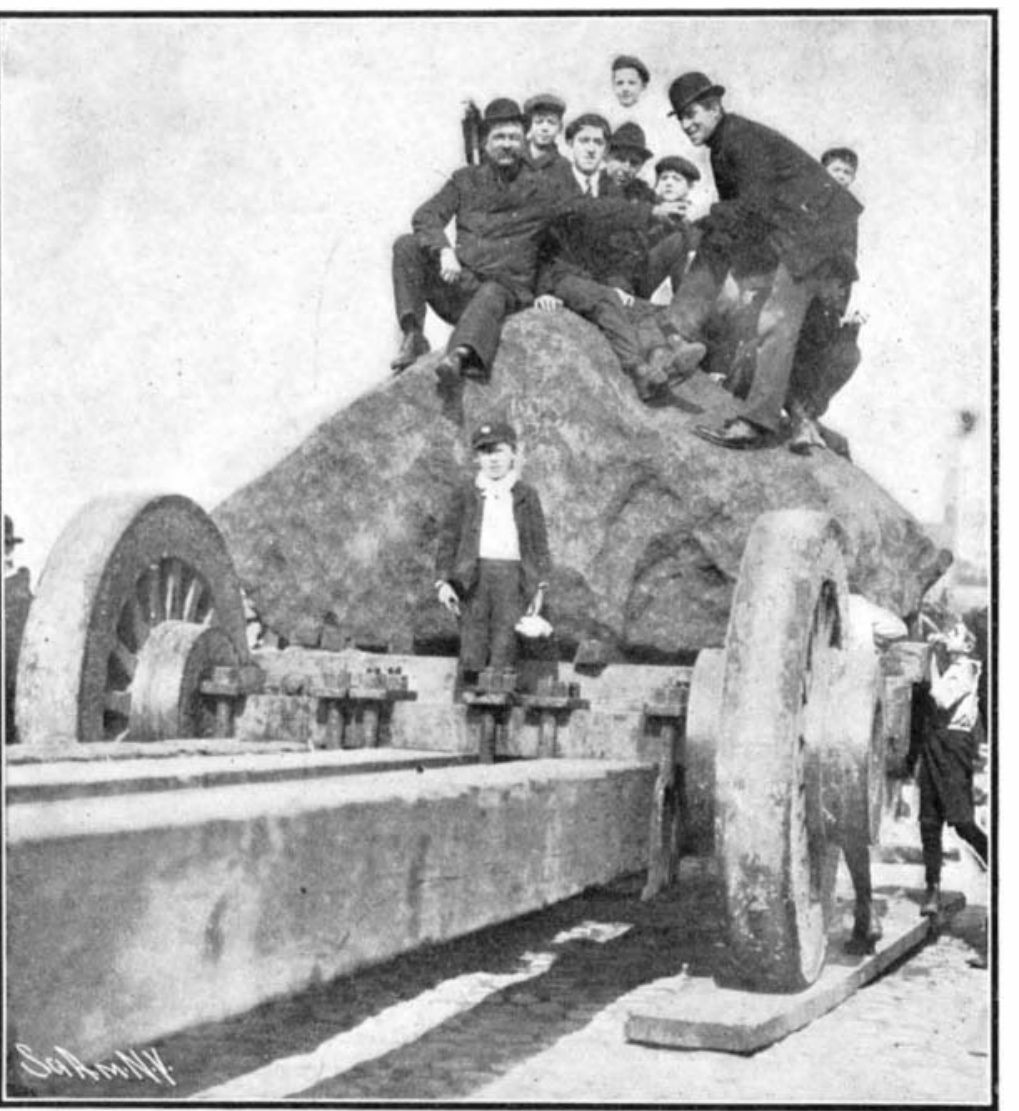

RMOVING THE PEARY METEORITE TO THE AMERICAN MUSEUM OF NATURAL HISTORY.

For hundreds of years prior to the advent of white communication the natives obtaine their scanty iro supply for knives, hatchets, harpoons and arrow-heads from their iron mountains. Piles of blue trap rocks used by them in pounding off fragments of their god for making their weapons were found near by. Several of these interesting relics, so closely associate with the big meteorite, were brought back by Lieut. Peary among the Eskimo collection of the Museum.

\section{THE AERIAL BRIDGE AT DULUTH.}

The unusual form of bridge shown in our illustration will possess decided novelty to American eyes, for it is the first of its kind to be built in this country. It was erected in accordance with an agreement for perpetual free ferry service made by the city of Duluth in consideration of a grant of right of way for the Unite States ship canal at that port. For many years, two old-fashioned flat-boats plied half-hourly between the two landing points; but as the canal widened, this primitive mode became extremely incon venient, not to say dangerous, and tugs were hired to take their place. With each succeeding year the expense increased, and the perpetual ferry began to loom up before the city fathers as quite a leading question. Numerous alternative plans were discussed, and for one reason or another abandoned. The estimated cost of a tunnel-about one million and a half dollars-rendered that form of communication out of the question, and the War Department refused to allow a drawbridge of any kind. One of the mayors of the city, however, had seen and been much impressed with the aerial bridge which was opened a few years ago at Rouen, France; and its applicability to the conditions at Duluth was so apparent, that this type was readily adopted. The present bridge was planned on the principles of the Rouen structure, and it will no doubt prove to be a satisfactory solution of the problem. Although the structure will be the first of its kind in America, it is not by any means novel in the engineering world, as there are in Europe to-day three bridges of the same general type: The one mentione at Rouen, France, over the Seine; another at Pt. Egalite, Spain; and the thir at Bigerta, Tunis.

The bridge at Duluth, as will be seen from our engravings, is a decidedly imposing structure. It consists of two piers or towers on shore, supporting a deep truss which spans the open waterway. There is nothing special in the details of this work, the piers being of the standard type used in steel railway viaducts, the truss being of the usual American design with long panels and single intersections. The posts are vertical on the side facing the channel, the other two posts on the land side being batter ed to give the necessary stability. In the erection of the structure the piers were first built to their full height, and then the trusses were erected by the overhang method, a temporary timber bent being used to support the first panel of the truss, and the rest of the overhang being erected from traveling derricks mounted upon the top chords. At the time our photograph was taken the last section of the top chord was being lifted into place by the derricks. From the water-line to the bottom of the trusses is 135 feet, and as the truss is 50 feet deep, the highest point is 185 feet above the water. The clear span between towers is 381 feet 6 inches. Special attention was given to wind pressure, the bridge being built to withstand a wind velocity of seventy miles per hour blowing transversely to the axis of the bridge. The traveling car will be suspended from the lower chords by stiff cables, and its floor will be 12 feet above the water level. The tance between landing points will be made in one and one-half minutes, and the schedule for trips will be arranged by the War Department soon after the completion of the bridge. The car measures 20 feet by 30 feet, and it has a capacity of 65 tons. The total cost of the structure will be about $\$ 110,000$.

The French Admiralty recently carried out an in teresting experiment to ascertain whether the explosion of a tor pedo in the vi. cinity of a submarine exercises any injurious effect upon another torpedo lying alongside the vessel. Th e submarine an. chored off Ca p e Petet and the torpedo, containing a charge of $100 \mathrm{killo}$. grammes of gun cotton was fired at a
distance of 50 meters from the $\mathrm{subma}$ $r$ in e, beside wh i ch, ex. posed to the full force of the exploding torpedo, was placed the secon d weapon. Not the slight. est a mage was caused by the explosion. 